\title{
Vocabulário controlado para acervos fotográficos: iniciativa e desenvolvimento no Arquivo Histórico de São Paulo
}

Ivany Sevarolli ${ }^{1}$

Arquivo Histórico de São Paulo

Ricardo Mendes ${ }^{2}$

Arquivo Histórico de São Paulo ${ }^{3}$

\section{Resumo}

O projeto Descrição Arquivística, implantado no Arquivo Histórico de São Paulo, unidade da Secretaria Municipal de Cultura, procurou estabelecer parâmetros para o gerenciamento de um vocabulário controlado que refletisse a natureza de um arquivo público, expressão das ações da municipalidade no gerenciamento da cidade. Em princípio voltado para a coleção fotográfica, esse trabalho exigiu a integração conceitual com a totalidade do acervo, bem como a interação com ferramentas conexas, com diferentes graus de desenvolvimento, como sistema de classificação, tipologia documental e autoridades arquivísticas.

Palavras-chave: Vocabulário controlado. Fotografia. Arquivo público.

Controlled vocabulary for photographic collections: initiative and development at the Arquivo Histórico de São Paulo

The Archival Description Project, implemented by the Arquivo Histórico de São Paulo, sought to establish parameters for managing controlled vocabulary in order to reflect the nature of a public archive, expression of the actions of urban management. First oriented to the photographic collection, the final work required the conceptual integration regarding the whole collection, as well as the interaction with 
tools, with different degrees of development, such as the classification system, documentary typology and archival authorities.

Key-words: Controlled vocabulary. Photography. Public archive.

Durante as duas últimas décadas, a ampla adoção do gerenciamento eletrônico de dados em instituições no campo da história social trouxe a consciência da necessidade de ferramentas voltadas para a otimização dos mecanismos de busca.

Vocabulários controlados, thesauri e iniciativas afins aplicadas a acervos iconográficos surgem de modo mais efetivo no período. Com a disponibilização pela internet, os novos instrumentos de busca tornam-se visíveis a um público ampliado, e a busca de eficiência é agora ponto crucial: na estruturação de interfaces, na sua operação etc., mas também no tratamento da informação e na própria reestruturação das bases.

No campo dos acervos fotográficos, o desenvolvimento em seu conjunto foi, contudo, irregular e pouco estudado entre nós, apesar do número crescente de instituições que conseguiram operacionalizar suas propostas.

É necessário apontar que, em 1993, iniciativa reunindo diversas instituições sediadas no Rio de Janeiro resulta no Manual para catalogação de documentos fotográficos: versão preliminar (FUNARTE; FBN, 1993). Essa edição reunia representantes da FUNARTE-IBAC, Fundação Biblioteca Nacional, Museu Histórico Nacional, Museu Imperial e Centro de Pesquisa e Documentação de História Contemporânea da Fundação Getúlio Vargas (FGV/CPDOC). Três anos depois, a Fundação Biblioteca Nacional edita o Manual para indexação de documentos fotográficos: versão preliminar (FBN, 1996), republicado em versão final em 1998.

Em São Paulo, no campo das artes visuais, o Instituto Cultural Itaú lança em 1992 a publicação Vocabulário Controlado de Arte (ICl, 1992). Aqui em tiragem restrita, circulando entre colaboradores. Seria oportuno reforçar que essas publicações 
precedem o surgimento da internet em sua fase pública no Brasil e algumas continuam sendo empregadas como referência.

Ao longo daquela primeira década, instituições das mais diversas naturezas detentoras de coleções iconográficas - bibliotecas, centros de documentação, museus, arquivos - desenvolvem projetos próprios de automatização ou implantam serviços com produtos terceirizados para gerenciamento eletrônico de acervo. Constituem projetos de perfis variados, de difícil comparação num primeiro momento, atendendo a uma matriz de funções diversas, como catalogação, consulta local ou on-line, gestão de empréstimos (de livros a obras de arte) etc.

Nesse período, surge em São Paulo como primeira referência do uso relevante da tecnologia digital para acesso a acervos o Banco de Dados Informatizado Módulo Fotografia (ICl, 1991), implementado pelo Instituto Itaú Cultural no início da década de 1990, voltado para a difusão da coleção de imagens digitais sobre a cidade de São Paulo. Essa experiência, de grande repercussão, precede a disponibilização via internet, utilizando bases replicadas em diferentes unidades regionais da entidade. A iniciativa não teve desdobramentos similares na década seguinte, ainda num recorte paulistano.

Basta lembrar que ainda hoje acervos significativos, como os do Museu PaulistaUSP, Museu da Imagem e do Som (MIS), Centro Cultural São Paulo (CCSP) e Instituto Moreira Salles não oferecem esse serviço on-line. Por outro lado, são muito diversificados os formatos das interfaces, as opções de consulta e as tecnologias adotadas pelos portais que oferecem essa possibilidade. O serviço é disponibilizado por instituições de escala e perfil diferenciados, como o Arquivo Público do Estado de São Paulo, Arquivo Histórico de São Paulo (AHSP), objeto do presente artigo, Museu da Energia (Fundação Energia e Saneamento), Museu Lasar Segall e mesmo o hotsite Tesouros da Cidade, portal da coleção de obras raras da Biblioteca Mário de Andrade.

Num esforço futuro para historiar esse desenvolvimento será fundamental considerar as experiências relativas ao campo do jornalismo através dos portais de periódicos 
(ou suas agências) como Folha de S. Paulo e O Estado de S. Paulo e de agências especializadas em jornalismo e publicidade.

A memória de trabalho dessas iniciativas pioneiras constitui um testemunho valioso sob risco iminente de dissolução. Além da dinâmica natural das equipes de trabalho, a adoção plena da rede internet traz novas mudanças, muitas vezes rupturas de processos de trabalho, que exigem registro e análise.

\section{O Arquivo Histórico de São Paulo: conjuntos iconográficos}

No âmbito do AHSP, unidade da Secretaria Municipal de Cultura (SMC), os instrumentos de pesquisas disponíveis nos últimos 20 anos permaneceram estáveis, diferenciando-se por vezes em função da natureza de conjuntos documentais ou de demandas específicas ao longo do tempo.

Respondendo pela guarda da documentação gerada pela administração municipal, o Arquivo Histórico, através do seu acervo, registra a gestão da cidade e a evolução da estrutura administrativa ao longo de quatro séculos, mapeando as ações da municipalidade e a interação entre a sociedade e o governo.

Data de 1984 a publicação do primeiro guia do acervo, permitindo ao público uma visão geral sobre os fundos custodiados na ausência de outros instrumentos de pesquisa com essa finalidade até então. As edições posteriores, realizadas em 2000 e 2007 (ARQUIVO HISTÓRICO MUNICIPAL WASHINGTON LUÍS, 2007), esta também disponível on-line, aprofundaram a descrição do acervo. Essas publicações permitem também identificar a expansão do conjunto documental, seja pelo crescimento dos anos limites de vários grupos, seja pela incorporação de fundos particulares ${ }^{4}$. Os guias registram ainda as mudanças das instalações e alterações na gestão documental.

É necessário apontar que a descrição de fundos na edição de 2007 não é homogênea, variando, por exemplo, o grau de detalhamento (grupo, série...) e mesmo assim com alguns conflitos na classificação. Exemplo disso é o Fundo Comissão do Quarto Centenário da Cidade de São Paulo, que, considerando-se sua forma de constituição, deveria integrar o Fundo Prefeitura Municipal de São Paulo. 
Essa edição, dado relevante a mencionar, não adotou o formato de descrição NOBRADE (CONSELHO NACIONAL DE ARQUIVOS, 2006). No entanto, pode-se justificar tal decisão se considerarmos que a fase de produção do guia coincidiu então com a etapa de consulta pública daquela norma ${ }^{5}$.

A consulta documental, considerando o conjunto do acervo, é ainda hoje predominantemente presencial. Em alguns casos, como o relativo ao Serviço Funerário, é possível o pedido de consulta via e-mail, prática adotada no início da década de 2000, o que foi possível em função da pesquisa nesse conjunto ser feita agora pela equipe interna. Há quase dois anos, o AHSP pôde disponibilizar instrumentos de pesquisa on-line, como os relativos ao acervo fotográfico, a partir de dezembro de 2011, como veremos adiante, ou ao conjunto processado pelo projeto Arquivo Histórico Municipal Washington Luís: a cidade de São Paulo e sua arquitetura $^{6}$, que permite acesso parcial a documentação da série Obras Particulares, composta por processos de aprovação de construções e reformas.

A consulta, considerando a globalidade do acervo, não dispõe de instrumentos de pesquisa estruturados, à exceção dos dois últimos conjuntos mencionados. acesso, de forma geral, é feito por referência cronológica, complementada por referências adicionais de natureza geográfica ou onomástica, conforme a documentação a ser examinada. O acesso conta com o apoio eventual de listagens organizadas por conjuntos específicos, sem qualquer padronização do conjunto.

Desse modo, embora o acervo institucional esteja disponível integralmente, grande parte do conjunto tem efetivamente acesso restrito, considerando a dificuldade de recuperação de dados, o que exige a consulta direta à documentação original por parte do pesquisador. Some-se a isso a ausência de um plano de classificação pleno substituindo a organização vigente, que peca pela heterogeneidade e extensão limitada.

Essa situação permitiu a sobrevida de instrumentos muito antigos e precários, como o uso de listagens não padronizadas, cobrindo os principais conjuntos demandados, e o apoio de anotações improvisadas produzidas pelos atendentes durante o 
processo de trabalho. Disso resulta, como em tantas instituições assemelhadas, a personificação do próprio instrumento de pesquisa na figura do atendente.

Há quase 10 anos o AHSP deu início ao processo de gestão eletrônica do acervo ao implantar o Sistema de Registro, Controle e Acesso a Acervo (Sirca) (ARQUIVo HISTÓRICO DE SÃO PAULO, [s.d.]). Cobrindo conjuntos de natureza e estrutura informacional distintas, a iniciativa procurou dar conta dessa diversidade, embora restrita por anos em sua operacionalização à documentação textual. Desenvolvido em Microsoft Access, o sistema teve uma primeira fase de migração para linguagem SQL em 2010 entrando em revisão a partir de 2012, o que implicou na suspensão temporária da alimentação e consulta de dados.

Deve-se mencionar que o sistema Sirca, ao longo de seu desenvolvimento, não foi orientado para a consulta direta pelo pesquisador externo, mantendo-se como instrumento de uso dos atendentes e equipe técnica. Além disso, durante o projeto não foi desenvolvido um módulo específico para fotografia, reflexo provável da ausência na instituição de uma orientação adequada para documentos iconográficos em geral.

\section{O acervo fotográfico}

Os documentos em suportes iconográficos custodiados apresentam conjuntos variados, alguns deles de intensa demanda nas duas últimas décadas, como as peças gráficas constituídas por projetos de edificações reunidos na Série Obras Particulares. Os demais suportes iconográficos cobrem espectro amplo, como cartografia ou fotografia, mas seria o caso de apontar a existência em meio aos diversos conjuntos, entremeados aos processos, das mais diversas espécies, como cartazes de cinema, bilhetes de loterias, papéis acionários etc.

O perfil da coleção fotográfica inclui três unidades temáticas predominantes:

a) documentação urbana, associada à ação direta da municipalidade, reunindo registros, por exemplo, de pavimentação de logradouros, aberturas de vias, construção de edifícios públicos etc.; 


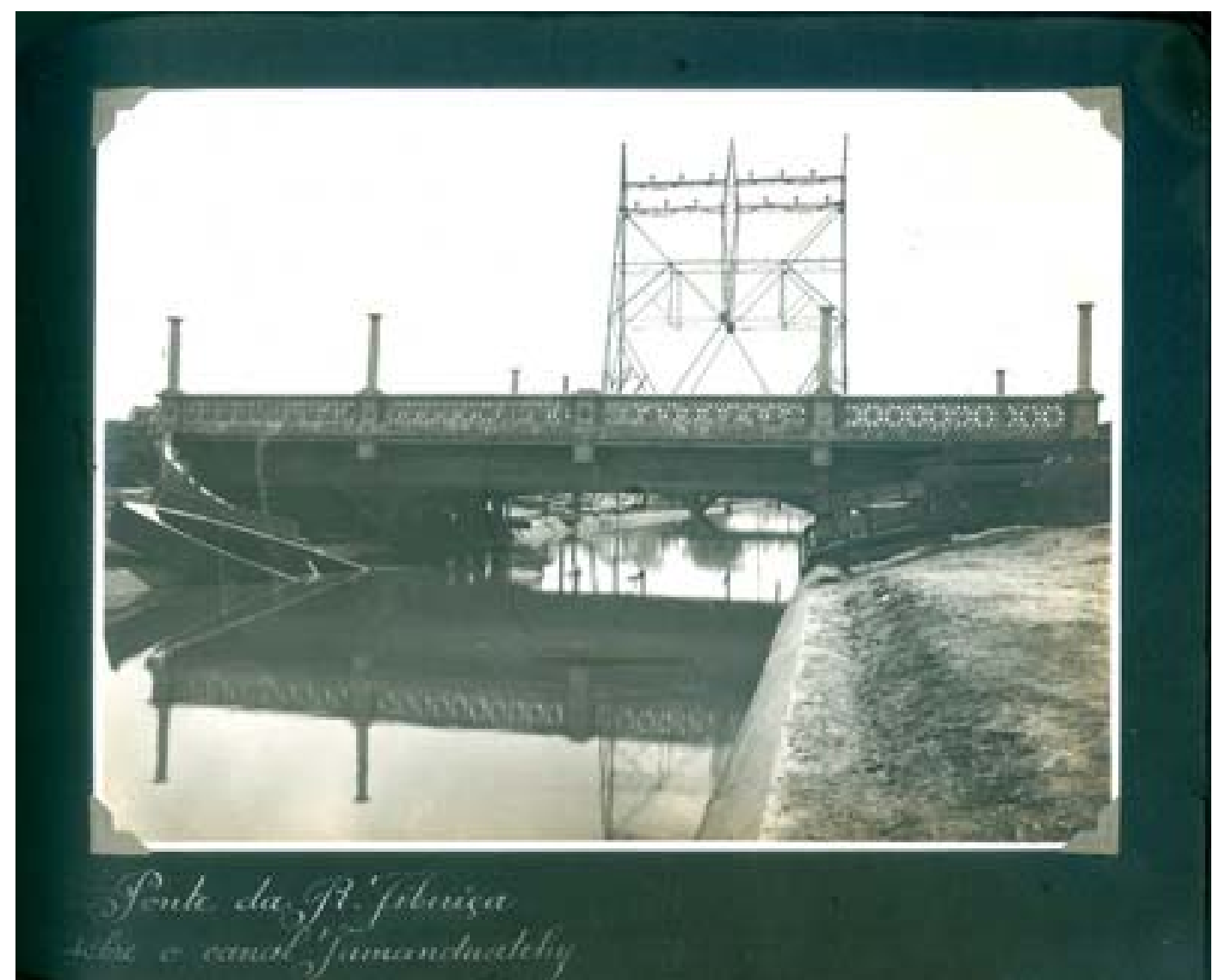

Figura 1 - Ponte da R. Tibiriça sobre o canal Tamanduatehy (sic). In: Prefeitura Municipal de São Paulo. Administração José Pires do Rio. Directoria de Obras e Viação: 1a Secção Technica: 1926 1930. São Paulo: [1930] (álbum fotográfico). Fotografia: autor desconhecido. Acervo AHSP.

b) assessoria de imprensa, reunindo documentação gerada na cobertura das ações dos prefeitos, como inaugurações, eventos políticos etc.; 


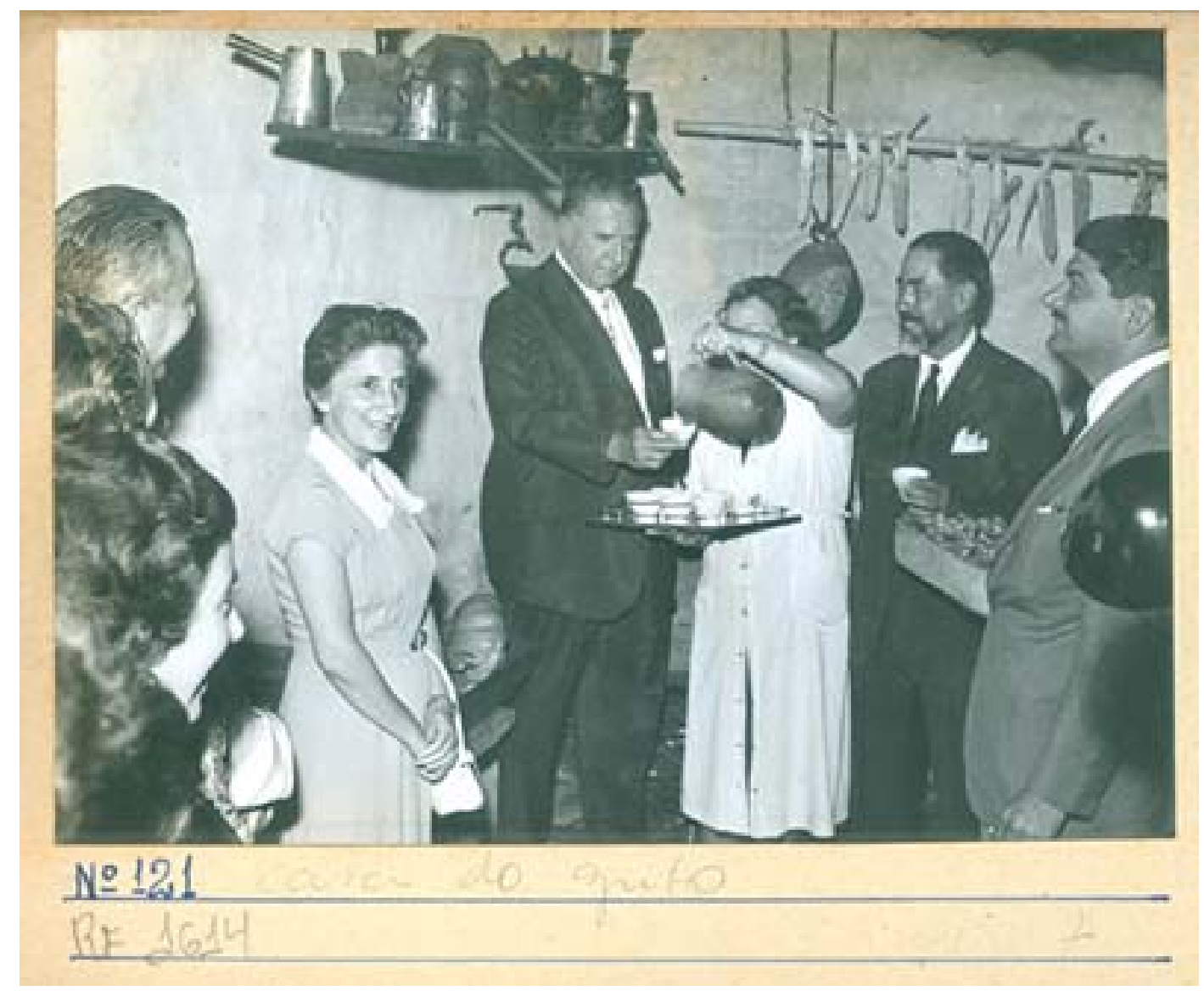

Figura 2 - Inauguração da Casa do Grito, com o prefeito Adhemar de Barros, 1958. In: Prefeitura Municipal de São Paulo. Administração Adhemar de Barros. [Monumentos]. São Paulo: [1960] (álbum fotográfico). Fotografia: autor desconhecido. Acervo AHSP.

c) fundos particulares, incorporados nas últimas duas décadas, os quais reúnem a memória visual de personalidades, conjuntos esses marcados pela presença de outros gêneros fotográficos, como retratos de família, cenas de viagem ou lazer, retratos em estúdio ou ambientes domésticos etc., que registram a vida social pública e privada de seus titulares. 


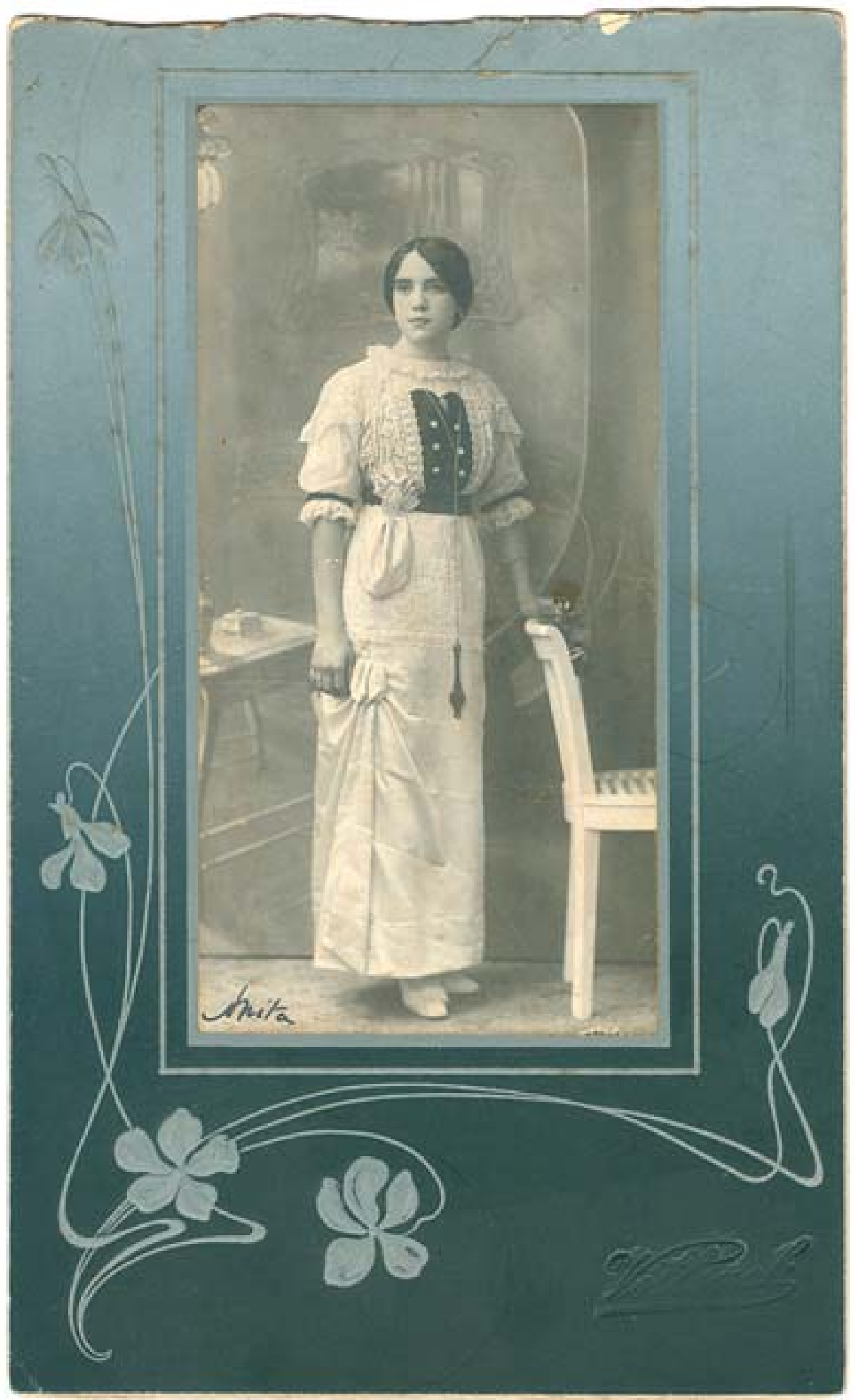

Figura 3 - Anita da Silva Prado, ca 1910. Fundo Particular Armando Prado. Fotografia: José Vollsack. Acervo AHSP. 
A coleção fotográfica, em boa parte reunida de origem em álbuns, está disponível para consulta há pelo menos 30 anos. Como instrumento de busca, esse conjunto contava com fichas por logradouro ou obra pública. Na edição de 2007 do guia do acervo, tanto a "coleção de fotografias" como os fundos particulares são apenas mencionados.

Em 2008, o AHSP apresentou ao Programa de Apoyo al Desarrollo de Archivos Iberoamericanos (ADAI), do Ministério de Educación, Cultura y Deporte da Espanha, uma proposta para intervenção ampla sobre a coleção fotográfica com objetivo de sistematizar os procedimentos de organização, preservação e acesso. 0 programa ADAI dispõe de uma linha de fomento internacional coordenada pelo governo espanhol que oferece regularmente bolsas de médio porte.

O perfil da coleção, a pequena dimensão do conjunto (então, ao redor de cinco mil unidades) e as ações programadas eram adequadas ao edital. A solicitação encaminhada propôs os seguintes objetivos:

- contribuir para a preservação dos originais fotográficos;

- agilizar o acesso aos conteúdos visuais;

- disponibilizar dados para a administração pública da cidade;

- garantir ao munícipe e ao público em geral seu direito à informação e à memória.

Em março de 2009 o projeto contemplado - Da Relíquia ao Virtual: organização do conjunto de fotografias que integram os diversos fundos documentais do Arquivo Histórico Municipal Washington Luís - é disponibilizado em consulta local. Ao final de 2011 o conjunto ganha sua interface on-line.

O projeto, em seu conjunto, reflete outras ações voltadas para o estudo metodológico do gerenciamento de coleções fotográficas. Destacam-se assim os artigos apresentados pela coordenadora da coleção, Ivany Sevarolli, no

V Congresso Brasileiro de Pesquisas Ambientais e Saúde - CBPAS'2005 (SEVAROLLI, 2005) e no World Congress on Computer Science, Engineering and Technology Education (RODRIGUES; SEVAROLLI, 2006) ${ }^{7}$. 
Os objetivos gerais do projeto foram traduzidos nas seguintes ações:

- tratamento dos objetos fotográficos para a preservação física (higienização, troca de embalagens etc.);

- tratamento arquivístico das informações relativas a conteúdo, produção e circulação das fotografias para inserção no processamento documental;

- informatização dos dados visuais e textuais para acesso por parte dos pesquisadores (estruturação e implantação da base de dados, inserção de dados, digitalização etc.);

- divulgação do serviço (evento de lançamento, edição de folheto de apresentação, inserções de notas no Informativo AHSP e na revista Em Cartaz, editada pela SMC).

De modo breve, o tratamento das informações abrangeu quatro fases: (1) o conceito de objeto fotográfico, (2) organização e classificação, (3) identificação e (4) interface de busca ${ }^{8}$.

A ação prioritária foi definir o registro documental de forma unitária, expressão do conceito de objeto fotográfico adotado, estabelecendo a unicidade por objeto e não por agrupamentos, como álbuns, séries etc.

A ausência de registro homogêneo exigiu a atribuição dessa referência única, numérica e sequencial a cada imagem fotográfica, para garantir acesso por item. Os objetos fotográficos que reúnem grupos de imagens como álbuns e alguns tipos de montagem $^{8}$ foram referenciados para recuperação por conjunto e por imagem simultaneamente.

Quanto à organização e à classificação, a principal dificuldade encontrada foi a ausência de uma versão revisada do sistema de classificação do acervo institucional. A situação era agravada com a exiguidade de informações a respeito da origem dos documentos fotográficos, fruto de um recolhimento nem sistematizado, nem documentado. A classificação disponível, quando existente, 
remetia apenas às diferentes gestões administrativas (especificamente, os prefeitos).

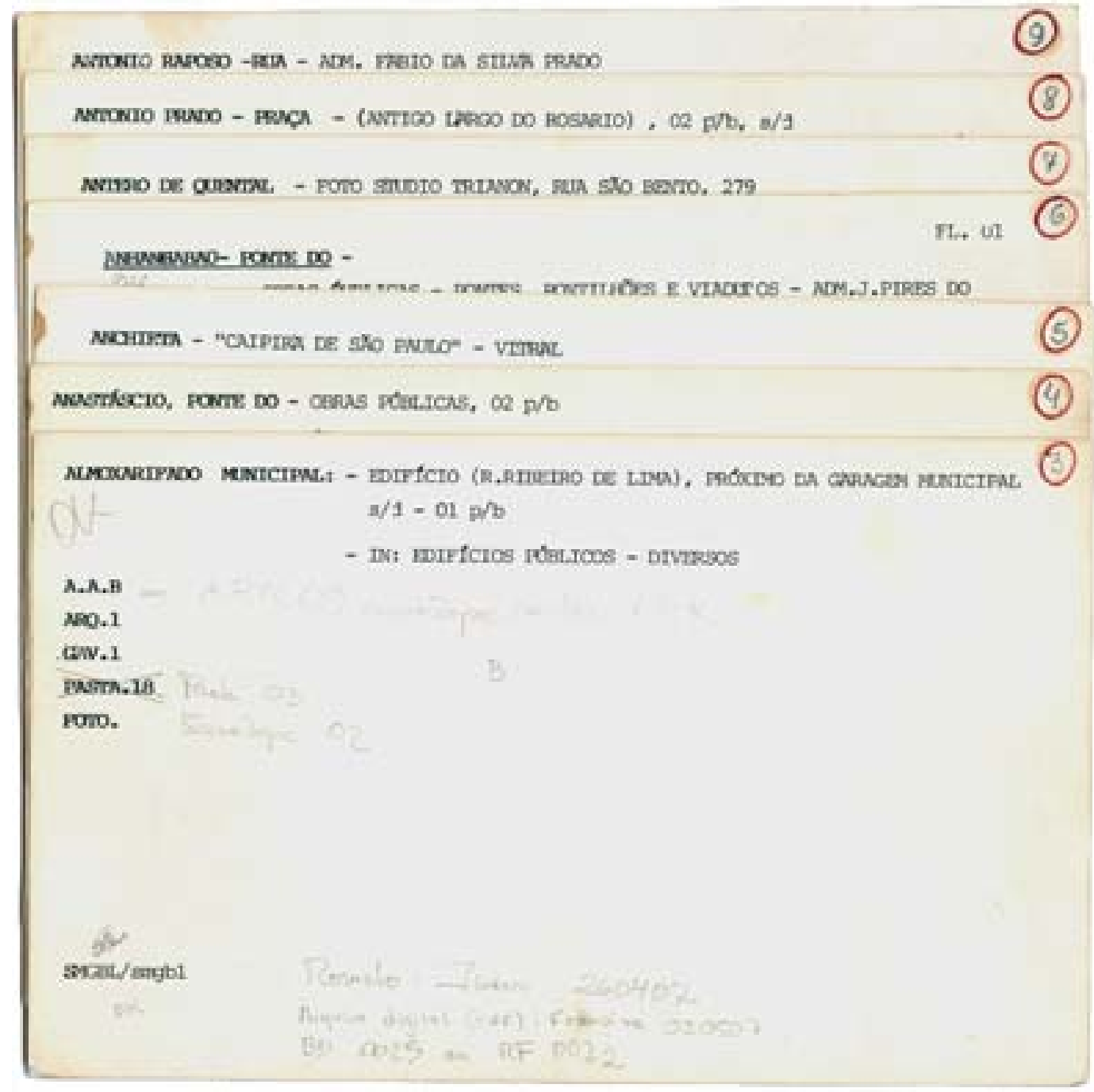

Figura 4 - Fichas do catálogo de consulta da coleção fotográfica, de uso corrente até 2009 e substituídas então pela base de dados do projeto Da Relíquia ao Virtual (Prefeitura Municipal de São Paulo, 2008-2009).

$\mathrm{Na}$ fase inicial foi desenvolvida a organização dos itens, priorizando os documentos fotográficos gerados pelas atividades-fim da instituição (a municipalidade) e aqueles documentos integrantes dos Fundos Particulares. Assim foram preteridas imagens utilizadas em exposições ou publicações, por exemplo, que fossem reproduções de originais custodiados por outras instituições. 
A data de produção das imagens, estimada quando inexistente, permitiu então a classificação do conjunto em acordo com a estrutura dos fundos públicos municipais frente à ausência de dados sobre o recolhimento (expedientes de encaminhamento, termos de doação etc.).

No processo de identificação, buscando atender ao cronograma do projeto ${ }^{10}$, foi estabelecida uma estrutura sumária de dados para cada unidade, articulada em três áreas: classificação/procedência, descrição técnica e descrição de conteúdo ${ }^{11}$. Para recuperação ampliada foram atribuídas, além do campo assunto geral, três entradas complementares para descritores de conteúdo.

A primeira versão da interface de busca, disponível em março de 2009 ainda em acesso local ${ }^{12}$, permitia uma consulta limitada a campos gerais: identificação, data, local, autoria. Com a versão on-line de acesso público, ao final de 2011, a recuperação foi ampliada, incluindo os campos: autoria, tipo (suporte) e categoria (gênero). Foi oferecida ainda a possibilidade de busca específica nos campos: data, identificação e localização (bairro).

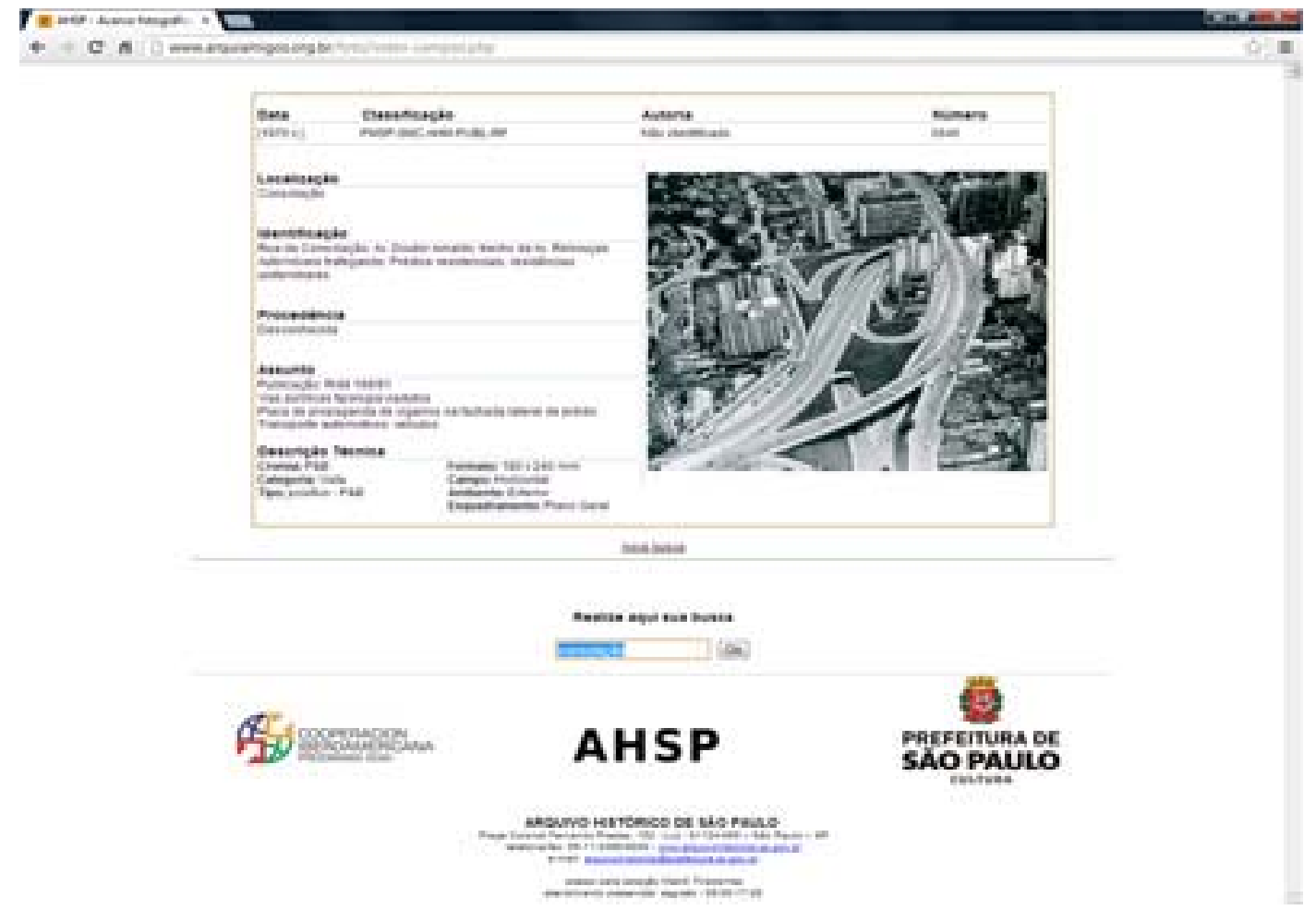

Figura 5 - Resultado de busca na base de dados online na página institucional. Disponível em: <http://www.arquivohistorico.sp.gov.br>. 


\section{O projeto Descrição Arquivística}

Nos últimos anos, a disponibilização de acervos via internet tornou-se uma marca do período. Assim, em 2010 a Secretaria Municipal de Cultura decide implementar um portal de acervos que permitisse acesso unificado a suas coleções artísticas e culturais não livro. Nesse contexto, a necessidade de desenvolvimento de vocabulário padrão se impôs ao integrar acervos diferenciados.

A iniciativa resultou no portal Acervos artísticos e culturais da Prefeitura de São Paulo (PMSP, 2012), lançado em novembro de 2012. O site reúne 16 conjuntos, destacando-se no segmento fotográfico as coleções do AHSP, da Casa da Imagem (Museu da Cidade de São Paulo), Missão de Pesquisas Folclóricas (CCSP) e Etnográfico (Pavilhão das Culturas Brasileiras) ${ }^{13}$.

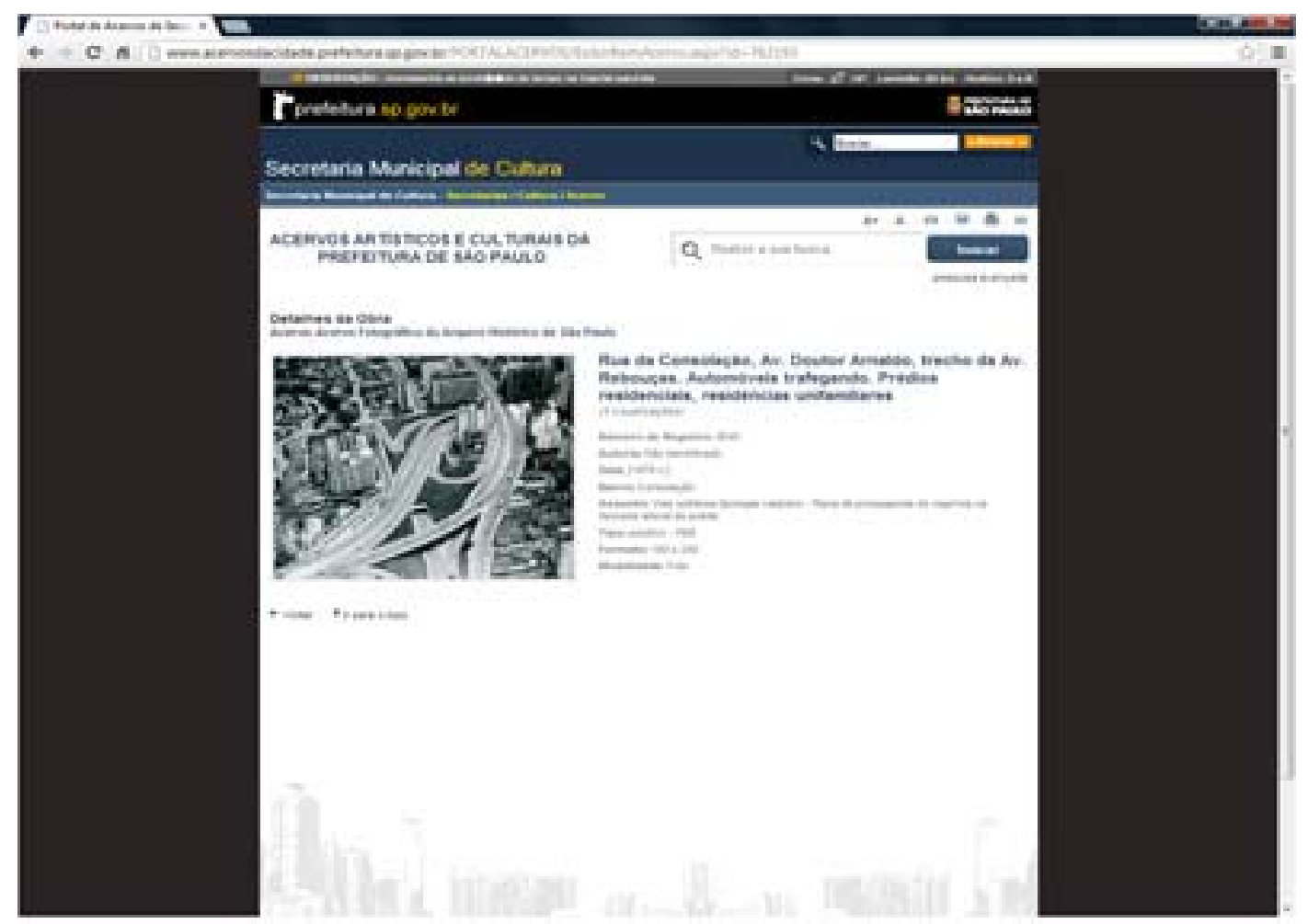

Figura 6 - Resultado de busca no portal Acervos Artísticos e Culturais da Prefeitura de São Paulo. Disponível em: <http://acervosdacidade.prefeitura.sp.gov.br>. 
Os trabalhos do GT Vocabulário Controlado, grupo de trabalho criado no segundo semestre de 2010 dentro daquele projeto, revelaram certamente a diversidade das abordagens em cada acervo, seus recortes documentais, mas em especial, orientações metodológicas conflitantes para uma integração em curto prazo.

Os participantes do portal com coleções fotográficas adotam práticas distintas, marcadas pelo uso e função dos conjuntos, próximos a campos como artes visuais ou etnografia, distantes dos parâmetros usuais para coleções abrigadas em um arquivo público.

Contudo, a participação nesse GT foi momento desencadeador de ação similar no âmbito do AHSP. Por um lado, na esfera da proposta para o portal da SMC buscouse promover o diálogo entre as diferentes abordagens. Por outro, o projeto implantado internamente procurou na fase inicial estabelecer parâmetros para o gerenciamento de um vocabulário controlado que refletisse a natureza de um arquivo público, cujo acervo expressa as ações da municipalidade no gerenciamento da cidade.

Em princípio voltado para a coleção fotográfica, o trabalho desenvolvido no AHSP exigia sua integração conceitual com a totalidade do acervo, bem como a interação com ferramentas conexas em diferentes graus de desenvolvimento, como sistema de classificação, tipologia documental e controle de autoridades.

A gestão da cidade e a relação entre governo e munícipe representam um elemento de distinção frente ao conjunto de acervos reunidos no portal Acervos Artísticos e Culturais da Prefeitura de São Paulo. Como arquivo público da cidade, os macrotermos devem refletir essas relações e seu desenvolvimento no tempo: da administração pública à economia, educação, eventos, governo, habitação, infraestrutura urbana, lazer e turismo, saúde, transportes etc.

Constituem, portanto, parâmetros ordenadores para o projeto de vocabulário controlado da instituição:

as áreas de atuação da municipalidade ao longo de sua existência (arruamentos, pavimentações, licenciamentos diversos etc.); 
o perfil da documentação custodiada, mas com atenção às práticas posteriores às datas limite, considerando futuras incorporações ${ }^{14}$;

a demanda dos usuários ao longo da história da instituição e dos usuários em potencial;

as obras de referência do setor, as práticas adotadas nas instituições correlatas ao AHSP e aquelas associadas às diversas áreas de conhecimento envolvidas.

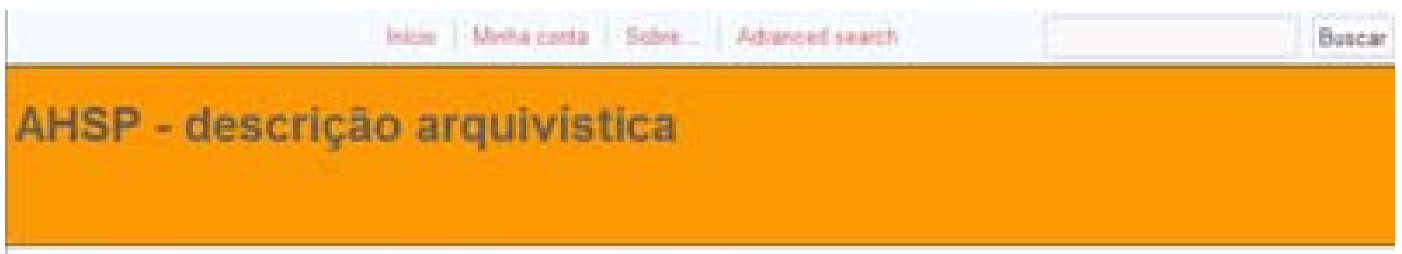

\section{transportes - bondes e tramways}

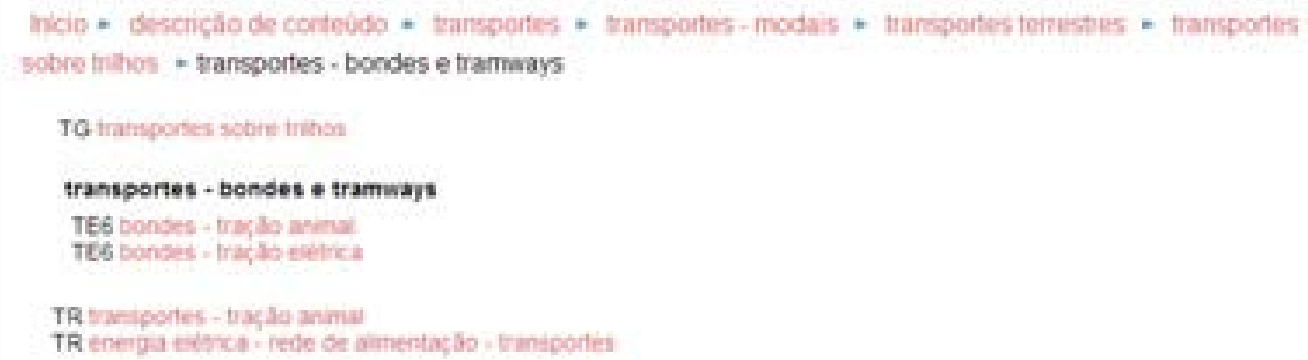

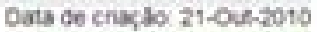

Terno aceits 21 -Out.2010

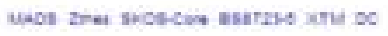

0.9ABCDEFลHUTKLIMNO PอRรTणVखz

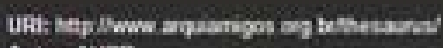

Auncer Resp

Crado por In malienst

penupois -

Figura 7 - Página internet do projeto Descrição Arquivística exemplificando a estruturação de um termo. Disponível em: <http://www. arquiamigos.org.br/thesaurus.htm>.

Representa novos desafios para a gestão dessa coleção a incorporação recente de dois conjuntos transferidos da Casa da Imagem de São Paulo. O primeiro, associado ao Gabinete do Prefeito, estende os limites temporais da documentação de assessoria de imprensa até $2008^{15}$. O segundo grupo recebido incorpora ao acervo 
levantamentos aerofotogramétricos realizados nas décadas de 1950 e seguinte, introduzindo um novo gênero fotográfico no conjunto.

Como fontes principais, sempre em diálogo com experiências no universo da secretaria, como o Tesauro de Acervos Fotográficos, desenvolvido pelo Museu da Cidade de São Paulo (2009), e a relação de termos gerados na gestão do Sirca, partimos de experiências marcadas tanto pela diversidade da tipologia institucional biblioteca, arquivo, museu - quanto pelas áreas envolvidas, como artes visuais, história social etc. ${ }^{16}$. Essa decisão era motivada em especial pelo desconhecimento naquele momento de experiências consolidadas de vocabulários controlados para acervos fotográficos em arquivos públicos.

Fontes adicionais mostraram-se valiosas, como, por exemplo, as relações de ocupações utilizadas pelo Ministério do Trabalho e Emprego na Classificação Brasileira de Ocupações (CBO) (BRASIL, 2002) e as relações de atividades econômicas estabelecidas pelo Instituto Brasileiro de Geografia e Estatística (IBGE) na Classificação Nacional de Atividades Econômicas (CNAE) (IBGE, 2013). A utilização dessas fontes é mediada sempre pelo recorte temporal da documentação custodiada, bem como pela atenção à evolução da estrutura administrativa municipal, em especial considerando as datas limites da coleção de imagens.

Aspecto-chave foi a adoção desde o início, na tentativa de manter um nível crítico sobre o processo, da noção de "suficiência" do termo. Busca-se assim promover um crescimento controlado atento às necessidades da instituição em médio prazo, evitando a ocorrência de uma hiperinflação de termos.

\section{A mediação digital}

Momento fundamental para o trabalho foi o processo de escolha de um programa eletrônico especializado para a gestão de vocabulários controlados. Além das ofertas comerciais, diversas iniciativas com código aberto ofereciam leque razoável de possibilidades para softwares. 
A primeira opção - em contraposição ao emprego de versões de demonstração (versões demo) de softwares comerciais para uso estrito em pequena escala e por vezes com opções não habilitadas - foi identificar experiências inovadoras independentes. O emprego de versões comerciais implicaria numa alteração imediata das condições de implantação do projeto que feriam o desenvolvimento em curto prazo e exigiriam recursos financeiros não previstos no orçamento anual.

A decisão final pelo programa TemaTres (FERREYRA, [s.d.]), desenvolvido na Argentina, levou em conta a facilidade de instalação e das operações de backup, migração, alimentação em lote ou emissão de relatório de controle, além das experiências relatadas no blog do fornecedor. Ao longo do projeto, contou-se com apoio do seu desenvolvedor - Diego Ferreyra -, inclusive na implementação de programa de visualização gráfica de dados ${ }^{17}$. Dessa forma 0 projeto pôde apresentar-se desde 0 início como ferramenta on-line ${ }^{18}$, aspecto valioso para 0 intercâmbio de experiências. Isso possibilitou a difusão do projeto entre a equipe técnica institucional e seu emprego.

Durante o primeiro ano, as atividades enfocaram a constituição de um núcleo geral para o vocabulário a partir de um núcleo (core) operacional construído criticamente através dos termos correntes relativos aos registros existentes na base de dados da coleção e da adoção de novos termos no confronto com as fontes empregadas. O crescimento do vocabulário atinge nos dois primeiros meses 1.039 termos, incluso aí os termos preteridos ${ }^{19}$.

Os meses iniciais registram, assim, um crescimento expressivo de termos, em parte baseado na análise dos vocabulários mais próximos, como os adotados pelo Museu da Cidade de São Paulo, e em menor grau pelo Sirca ${ }^{20}$. Além das relações de ocupações e atividades econômicas mencionadas anteriormente, experiências desenvolvidas em acervos conexos, como o da Fundação Energia e Saneamento ([s.d.]), com um instrumento de pesquisa específico para uma coleção de peças ligadas à área de iluminação artificial, foram meio valioso de troca de informações, em especial na eleição dos termos adotados. Nesse aspecto, considerando também a extensão das ações registradas pela documentação e o arco temporal implícito, a aferição eventual de ocorrências de termos em determinados conjuntos exigiu o 
diálogo com os responsáveis pelo processo de gestão como um todo, incluindo muitas vezes os atendentes e pesquisadores mais frequentes do acervo.

Ao mesmo tempo, nesse primeiro ano foram realizadas apresentações do projeto para o público interno. A partir dessas apresentações foram organizados encontros mensais de trabalho abertos aos técnicos da instituição e estagiários. Essas práticas não tiveram continuidade em 2012, em especial devido à exiguidade das equipes técnicas que impossibilitavam uma participação regular nas reuniões.

\section{As metáforas da árvore, do coqueiro e do bosque}

O processo complexo de análise e de tomada de decisões na constituição desse núcleo geral do vocabulário tornou evidente a necessidade de crítica metodológica permanente, como também a busca do diálogo interdisciplinar e a organização de balanços periódicos.

Com equipe mínima, dois técnicos (arquitetos, com especializações em história da fotografia e organização de acervos) e, a partir de 2012, um assistente com formação em história, o crescimento da árvore de termos teve lugar de forma por vezes pouco homogênea.

A insuficiência ou mesmo a ausência de certos instrumentos arquivísticos, como o sistema de classificação ou o controle de autoridades, gerou, por exemplo, a inserção de ramificações espúrias em longo prazo, mas necessárias, na arborização em andamento. Ao mesmo tempo, surgiam termos ao longo da gestão cotidiana da coleção que demandavam inserções o no vocabulário e exigiam, por vezes, a constituição de ramificações provisórias. Esses desenvolvimentos despendiam atenção especial da equipe, de modo a evitar que a metáfora da árvore desse lugar a do coqueiro, ou seja, o mero apêndice de cada termo diretamente aos macrotermos.

Com o tempo, essa mesma insuficiência e as tentativas de contorná-la levaram a uma agregação de ramificações que não diziam respeito efetivamente ao campo de 
descrição de conteúdo. Em abril de 2011 decidiu-se por estabelecer eixos conceituais, permitindo separar estruturas de naturezas e funções distintas.

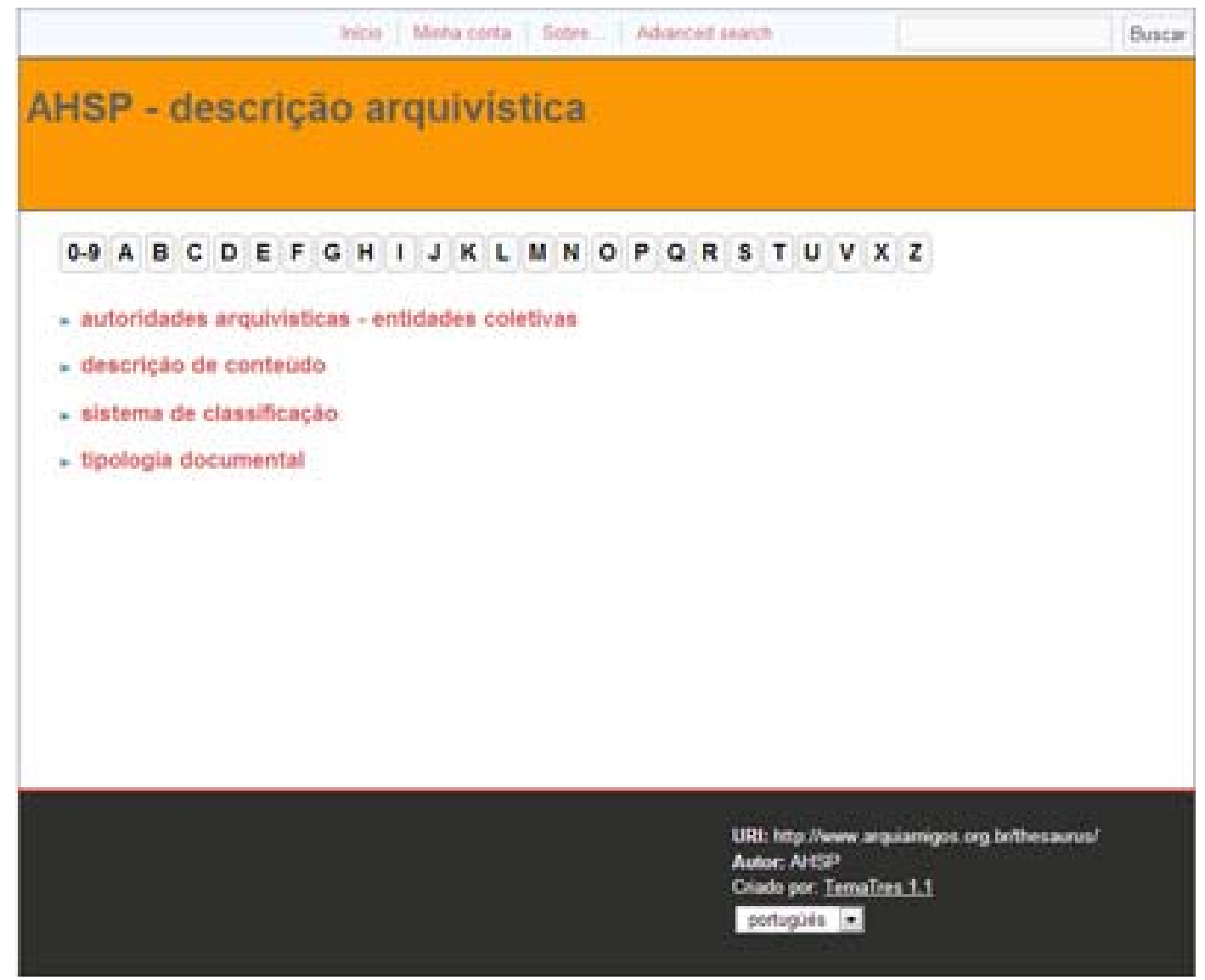

Figura 8 - Página de abertura no site do projeto Descrição Arquivística, exibindo os quatro eixos estruturadores. Disponível em: <http://www.arquiamigos.org.br/thesaurus.htm>.

Concebido inicialmente como vocabulário controlado, o escopo do projeto passou a ser a descrição arquivística, ganhando em abrangência e extensão e estabelecendo um terreno adequado para os parâmetros ordenadores da proposta. O conjunto foi assim reestruturado ao redor de quatro vetores, como forma de expressar e estimular a interação dos instrumentos arquivísticos como um todo:

- $\quad$ controle de autoridades (estrutura administrativa municipal);

- $\quad$ descrição de conteúdo;

- $\quad$ sistema de classificação;

- tipologia documental.

A metáfora do bosque surge, então, como referência, permitindo visualizar a existência e interação entre áreas do conhecimento. Essa alteração gerou a 
necessidade de definir fontes complementares para o trabalho. Adotaram-se como referências imediatas a transposição do sistema de classificação publicado no guia do acervo (ARQUIVO HISTÓRICO MUNICIPAL WASHINGTON LUÍS, 2007) e os organogramas da estrutura administrativa municipal publicados na Revista do Arquivo Municipal (BARROS; MOIZO, 1991).

\section{Como avançar?}

O diálogo interinstitucional parece ser agora etapa mais relevante para o desdobramento do projeto: diálogo em participações em eventos do setor, mas também através da organização de fóruns pela instituição gestora.

A discussão sobre desenvolvimento regular e melhor integração deve considerar ainda ações recentes, como a incorporação gradativa, no primeiro semestre de 2012, das planilhas de descrição de fundos do acervo fotográfico no formato NOBRADE.

Frente de trabalho importante é o melhor conhecimento da nova ferramenta Visual Vocabulary, incorporada em novembro de 2013, também fornecida pela TemaTres, que permite visualização gráfica da árvore de termos. A ferramenta é extremamente valiosa para análise dos termos e suas relações, bem como constitui uma forma adicional de consulta e recuperação. 


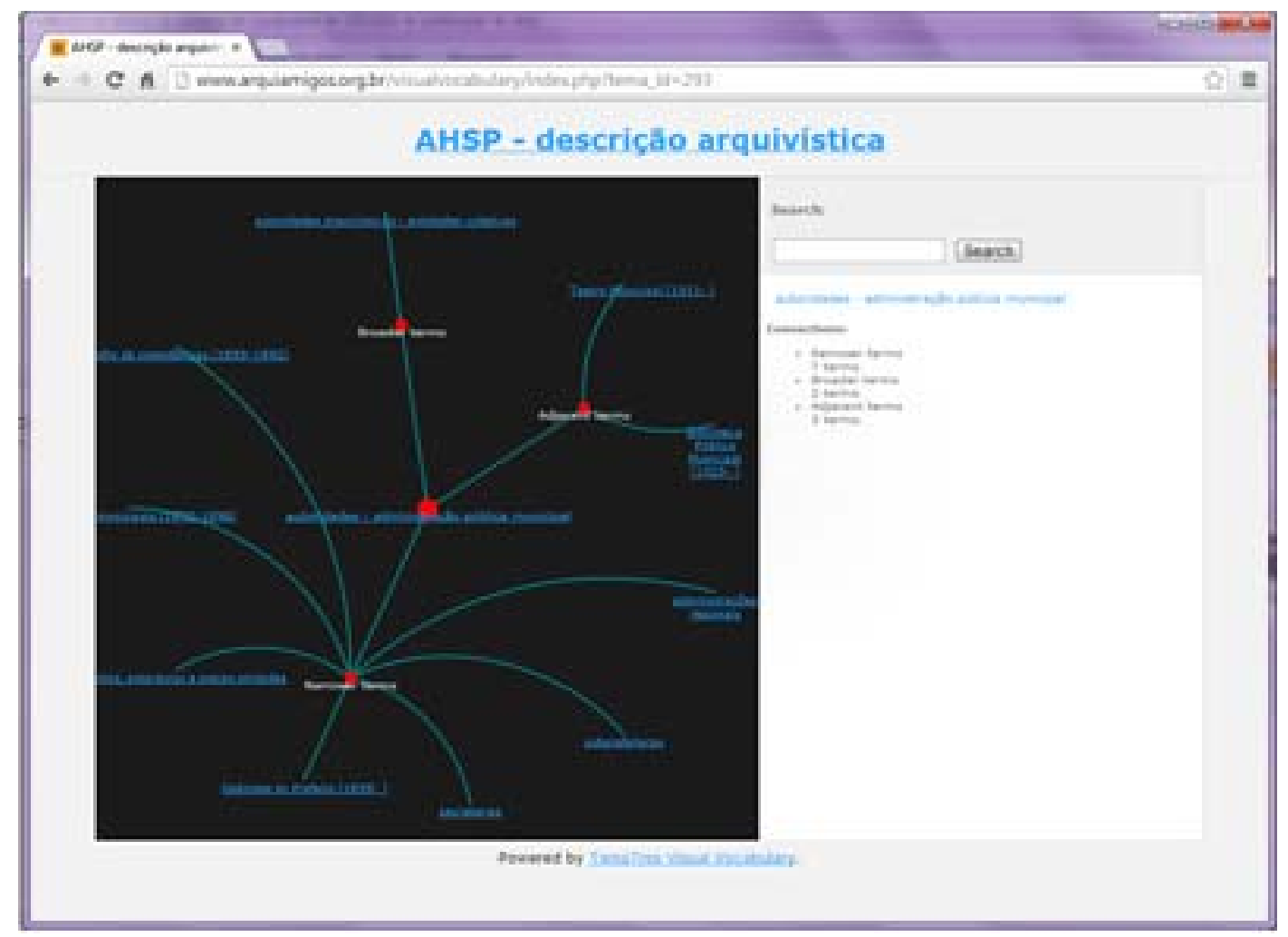

Figura 9 - Visualização gráfica de termos disponível no projeto Descrição Arquivística. Disponível em: <http://www.arquiamigos.org.br/thesaurus.htm>.

Avaliar periodicamente e de modo abrangente os vetores temáticos é um desafio. Para isso é necessário identificar instrumentos de análise que indiquem o grau de eficiência e adequação da estrutura de termos.

O crescimento da coleção, com a incorporação em dezembro de 2012 de novos conjuntos, implica em mudanças quantitativas e qualitativas que devem onerar o desenvolvimento do projeto em médio prazo e exigir uma adequação mais efetiva de equipe e carga horária.

O projeto Descrição Arquivística, por sua natureza intrínseca, demanda aspectos prementes, como a integração de equipes e a troca de informação em diferentes níveis. Para isso a comunicação apresentada no II Fórum sobre Patrimônio Cultural (abril de 2013) traçou uma memória do trabalho, buscando assim estimular a discussão de estratégias de desenvolvimento e pesquisas em controle de qualidade e sobre novas formas de acesso como a visualização de dados. 


\section{Notas}

(1) Bacharel em Arquitetura pela Faculdade de Arquitetura e Urbanismo Farias Brito. Mestre em Comunicação Social pela UNIP. Coordenadora do Acervo Fotográfico - Supervisão do Acervo Permanente AHSP/SMC/PMSP. E-mail: ivanysevarolli@gmail.com

(2) Bacharel em Cinema e Arquitetura pela USP. Mestre em Ação Cultural pela ECA-USP. Pesquisador do Núcleo de Produção Editorial - Supervisão de Pesquisa e Difusão - AHSP/SMC/PMSP. E-mail: rico@prefeitura.sp.gov.br

(3) O Arquivo Histórico de São Paulo recebeu essa denominação em maio de 2010 substituindo a anterior, Arquivo Histórico Municipal Washington Luís. O artigo mantém essas variações nas referências conforme as obras mencionadas.

(4) A partir da década de 1990 a instituição adotou o recolhimento de documentos provenientes de particulares, pessoas físicas ou jurídicas "desde que eles possuam estreita relação com a história da cidade". (ARQUIVO HISTÓRICO MUNICIPAL WASHINGTON LUÍS, 2007, p.43).

(5) A Norma Brasileira de Descrição Arquivística (NOBRADE) tem sua primeira edição, em versão preliminar, em setembro de 2005. A consulta pública teve lugar entre janeiro e maio de 2006, sendo a primeira edição datada de novembro de 2006 conforme cólofon (CONSELHO NACIONAL DE ARQUIVOS, 2006).

(6) O projeto em questão foi desenvolvido entre 2007 e 2010 numa parceria da FAU-USP e a instituição, com financiamento da FAPESP no âmbito do Programa de Pesquisa em Políticas Públicas.

(7) Veja ainda: SEVAROLLI, 2007.

(8) Para mais informações, veja também:

ARQUIVO HISTÓRICO MUNICIPAL WASHINGTON LUÍS (São Paulo, SP). Fotografias do acervo do Arquivo Histórico Municipal Washington Luís. Informativo AHSP, São Paulo, n.22, jan.-fev. 2009.

(9) O conceito de objeto fotográfico adotado procura respeitar a integridade da imagem fotográfica e seu suporte, que revelam nesse conjunto seus usos e funções em acordo com o momento de produção e o âmbito de circulação. Desse modo, variações de montagem de imagens similares foram consideradas unidades diferenciadas, sendo cada registro relacionado nos campos de descrição, bem como eventuais inscrições particulares a cada objeto (dedicatórias e outras notas), igualmente registradas em campos próprios. As ocorrências de imagens idênticas receberam numeração sequencial considerando o acervo já formado.

(10) De início, previsto para execução em 12 meses, o cronograma foi reduzido por questões de data de efetiva disponibilização dos recursos financeiros, resultando num prazo executivo de cerca de quatro meses. 
(11) Distribuídos conforme as três áreas mencionadas, os campos estabelecidos na fase de implantação são os seguintes: (a) área classificação / procedência: número de registro, classificação, procedência, localização no acervo, localização das cópias digitais; (b) descrição técnica: formato, tipo (suporte), cromia, estado de conservação; e (c) descrição de conteúdo: autoria, identificação, local, data, ambiente (interior/exterior), categoria (gênero), orientação do quadro, enquadramento, inscrições, assunto geral, assuntos complementares. Campos adicionais são utilizados para indicações de: responsabilidade e data de criação do registro, e responsabilidade e data da última alteração.

(12) No segundo semestre de 2009 foi possível estabelecer a consulta on-line, restrita, porém, à rede intranet da administração municipal. A página internet será substituída quando da integração do banco de dados da coleção fotográfica ao SIRCA, sistema de gerenciamento do acervo

(13) A responsabilidade pelo gerenciamento desses acervos, a partir de meados de 2013, passou a ser objeto de debate dentro das ações de reestruturação de SMC.

(14) Um exemplo simples seria o estabelecimento de termos para áreas como pavimentação de ruas estando atento ao longo período temporal da documentação e ao desenvolvimento tecnológico no seguimento.

(15) O conjunto incorporou ainda imagens enviadas diretamente da Secretaria Executiva de Comunicação, estendendo o limite temporal até fevereiro de 2013. Seria oportuno mencionar, embora fuja ao escopo principal do artigo, que essa incorporação ilustra um aspecto peculiar da produção digital de imagem atual ao reunir cerca de 300 mil itens (born digital) gerados em pouco mais de três anos.

(16) Entre as principais referências utilizadas, cuja relação consta no site do projeto, estão: Biblioteca Nacional, USP-SIBi, Library of Congress (EUA), Museu da Cidade de São Paulo (SMC), Museu da Energia, MASP, Museu Lasar Segall, Getty Vocabularies (EUA) e Iconclass (Holanda).

(17) TemaTres Visual Vocabulary (FERREYRA, [s.d.]).

(18) Disponível em: <http://www.arquiamigos.org.br/thesaurus.htm>.

(19) O total, em novembro de 2013, é de 3001 termos.

(20) Esse sistema apresenta apenas uma listagem de termos não estruturada. Além disso, com mencionado, a questão do documento iconográfico não foi contemplada na concepção do projeto, o que implica que mesmo para itens como pranchas de arquitetura a descrição de conteúdo é insuficiente.

(21) Para acesso à relação atualizada de instrumentos utilizados, consulte a página Descrição Arquivística, 20102013. Disponível em: <http://www.arquiamigos.org.br/thesaurus.htm>. 


\section{Referências}

ARQUIVO HISTÓRICO MUNICIPAL WASHINGTON LUÍS (São Paulo, SP). Guia Arquivo Histórico Municipal Washington Luís. São Paulo, 2007.

ARQUIVO HISTÓRICO MUNICIPAL WASHINGTON LUÍS (São Paulo, SP). O programa ADAI e o projeto "Da relíquia ao virtual". Informativo Arquivo Histórico Municipal, n.22, jan.-fev. 2009. Disponível em:

<http://www.arquivohistorico.sp.gov.br>. Acesso em: 1 fev. 2013.

BARROS, Liliane Schrank Lehmann; MOIZO, Rosana Pires Azanha. Formação administrativa da Cidade de São Paulo: 1554-1954. Revista do Arquivo Municipal, n.199, p. 9-112, 1991.

CONSELHO NACIONAL DE ARQUIVOS. NOBRADE: norma brasileira de descrição arquivística. Rio de Janeiro: Arquivo Nacional, 2006.

FUNARTE; FUNDAÇÃO BIBLIOTECA NACIONAL. Manual para catalogação de documentos fotográficos: versão preliminar. Rio de Janeiro: FUNARTE; FBN, 1993.

FUNDAÇÃO BIBLIOTECA NACIONAL. Manual para indexação de documentos fotográficos: versão preliminar. Rio de Janeiro: 1996.

INSTITUTO CULTURAL ITAÚ. Vocabulário controlado de arte. São Paulo, 1992.

MUSEU DA CIDADE DE SÃo PAULO (São Paulo, SP). Tesauro para acervos fotográficos. São Paulo, 2009.

RODRIGUES, André López A.; SEVAROLLI, Ivany. Da relíquia ao virtual: considerações sobre a digitalização de fotografias antigas com fins de disponibilização. In: WORLD CONGRESS ON COMPUTER SCIENCE, ENGINEERING AND TECHNOLOGY EDUCATION. Itanhaém, 2006. (CD-Rom)

SEVAROLLI, Ivany. O espelho de Annita: fotografia: meio e mensagem. 2007. Dissertação. (Mestrado em Comunicação - Cultura Midiática). Universidade Paulista (UNIP), São Paulo, 2007.

. O objeto fotográfico: uma contribuição à pesquisa e preservação de fotografias. In: V CONGRESSO BRASILEIRO DE PESQUISAS AMBIENTAIS E SAÚDE. Santos, 2005. (CD-Rom).

SMIT, Johanna Wilhelmina; KOBASHI, Nair Yumiko. Como elaborar vocabulário controlado para aplicação em arquivos. São Paulo: Arquivo do Estado/ Imprensa Oficial do Estado, 2003.

\section{BASES DE DADOS: GERENCIAMENTO ARQUIVÍSTICO}

ARQUIVO HISTÓRICO DE SÃO PAULO (São Paulo, SP). Sistema de registro, controle e acesso a acervo SIRCA. São Paulo, [s.d.].

INSTITUTO CULTURAL ITAÚ. Banco de dados informatizado módulo fotografia/Setor memória fotográfica da cidade de São Paulo. São Paulo, 1991-[1997]. 
SÃO PAULO (Cidade). Secretaria Municipal de Cultura. Acervos artísticos e culturais da Prefeitura de São Paulo. São Paulo, 2012. Disponível em: <http://acervosdacidade.prefeitura.sp.gov.br>. Acesso em: 1 mar. 2013.

\section{THESAURUS E VOCABULÁRIOS ${ }^{21}$}

BRASIL. Ministério do Trabalho e Emprego. Classificação brasileira de ocupações. Brasília, 2002. Disponível em: <http://www.mtecbo.gov.br/cbosite/pages/home.jsf >. Acesso em: 1 de março de 2013.

ECONOMIC AND SOCIAL DATA SERVICE. Humanities and social science electronic thesaurus. Reino Unido: [s.d.]. Disponível em: <http://www.esds.ac.uk/findingData/thesaurusInfo.asp>. Acesso em: 1 mar. 2013.

FUNDAÇÃO BIBLIOTECA NACIONAL. Terminologia de assuntos. Rio de Janeiro, 2000. Disponível em: < http://www.bn.br/site/pages/catalogos/terminologiaAssuntos/content.htm>. Acesso em: 1 mar. 2013.

FUNDAÇÃO ENERGIA E SANEAMENTO. Museu da Energia.Vocabulário controlado. São Paulo: [s.d.]. Disponível em: <http://www.museudaenergia.org.br>. Acesso em: 1 mar. 2013.

INSTITUTO BRASILEIRO DE GEOGRAFIA E ESTATÍSTICA. Classificação nacional de atividades econômicas: CNAE versão 2.0. Brasília, 2013. Disponível em: <http:/www.cnae.ibge.gov.br>. Acesso em: 1 mar. 2013.

LIBRARY OF CONGRESS (EUA). Authorities and vocabularies. Washington, [s.d.]. Disponível em: <http://id.loc.gov>. Acesso em: 1 mar. 2013.

MUSEU DE ARTE DE SÃo PAULO (São Paulo, SP). Vocabulário controlado de artes. São Paulo, 2009. Disponível em: <http://masp.art.br/masp2010/biblioteca_vocabulario.php >. Acesso em: 1 mar. 2013.

MUSEU LASAR SEGALL (São Paulo, SP). Thesaurus - fotografia. São Paulo, 2007. Disponível em: <http://www.museusegall.org.br>. Acesso em: 1 out. 2010.

NETHERLANDS INSTITUTE FOR ART HISTORY. Iconclass. The Hague: 2009. Disponível em: <http://www.iconclass.nl>. Acesso em: 1 mar. 2013.

UNIVERSIDADE DE SÃO PAULO. Sistema Integrado de Bibliotecas da Universidade de São Paulo. Vocabulário controlado do SIBiUSP. São Paulo, [s.d.]. Disponível em: <http://143.107.154.62/Vocab/Sibix652.dll/Index> Acesso em: 1 mar. 2013.

THE GETTY RESEARCH INSTITUTE. Getty vocabularies. Los Angeles, [s.d.]. Disponível em: <http://www.getty.edu/research/tools/vocabularies>. Acesso em: 1 mar. 2013.

\section{SOFTWARE}

FERREYRA, Diego. TemaTres. Buenos Aires, [s.d.] Disponível em: <http://tematres.r020.com.ar>. Acesso em: 1 fev. 2013. 
Recebido em 22 de abril de 2013

Aprovado em 30 de setembro de 2013 